\title{
The Exploration of the Teaching Mode Reform of the Basic Computer Courses for Non-Computer Majors---2010GZ083: the Key Project of 11th Five-Year-Plan of Shandong Province Education and Sci- ence
}

\author{
Qian Gao, Yushui Geng, Aizhang Guo, Yan Pan, Aimin Li \\ School of information, Qilu University of Technology, Jinan, China
}

\begin{abstract}
The current "one size fits all" and "zero" teaching methods in computer are clearly not suitable for the demands of the development of the current situation of higher education in information age. In this paper, I explored the teaching mode reform of the basic computer course for noncomputer majors, proposing three reform strategies that can keep pace with the information age, and four notes should be consideration in the process of teaching mode reform of basic computer courses.

Keywords: innovative practice, goaldriven, case teaching, credit conversion mechanism.
\end{abstract}

\section{Introduction}

The 21st century is the era of knowledge economy, and the core issue of knowledge economy is the innovation of knowledge. In the knowledge economy, and the core issue of knowledge economy is the innovation of knowledge. In the knowledge economy society, whether a large number of talents with knowledge innovation and technological innovation spirit can be cultivated will determine the success or failure of a country or nation in the international competition.

With the rapid development of information technology, the ability of acquiring information, processing information and using information has become the most basic survival ability for a modern person. Therefore, it has become the important goal for the development of education to developing students' ability of information processing and improves students' information literacy.

\section{Problems of Current Approach of College Basic Computer Courses Instruction}

\subsection{Education level is not clear and the teaching is lack of humaniza- tion.}

Due to different economic levels and the attention of high school information technology teaching, university freshman have uneven computer levels. According to the investigation of the freshmen of 2011 of our university, it is found that about $95 \%$ of the students have received computer education before entering the university. Among them, about $28 \%$ have 
a certain application base; some have even acquired the national computer level certificate. But most reported that they are lack of systematic study in spite of swallowing by rote; while about $5 \%$ of the students never or rarely contact the computer, and can't even boot shutdown computer.

\subsection{The computer knowledge and Professional knowledge are de- tached, cannot be put into prac- tice}

Students from different specialties, have different professional computer basis, so that training objectives should vary. But current computer basic teaching adopts general teaching content and the examples and experiments are always out of line with professional knowledge so as to make students feel that the basic computer knowledge learned has nothing to do with professional knowledge, which cannot be well applied to their specialty [1].

\subsection{Not familiar with computer relat- ed English professional terms and documents description}

Many definitions and idioms in computer can have some differences in meaning because of language differences. It is not easy for students to accurately understand and master the exact sense of definitions and idiom of the computer technology so as to cause cognitive misunderstandings if only Chinese is used in classroom.

\subsection{Students prefer online entertain- ment but are lack of computer application ability, and they study just for examination, ignoring Knowledge and Skill development}

Some students who often surf the internet thought that they knew how to use computer so that there was no need for them to have computer course. Some students are obsessed with online chatting and computer games and are not interested in the study of this course. Some who know nothing about computer knowledge feel arcane for computer application basis.

In conclusion, the present "one size fits all" and "zero" teaching methods in computer are clearly not suitable for the demands of the development of the current situation of higher education in information age.

\section{The Research Status at Home and Abroad}

The basic computer curriculum situation of well-known domestic universities: the basic computer courses of Beijing university of can be divided into two levels: (1) Computer Basis (1), which is compulsory course for Arts students, aiming to introduce the development of computer, the use and maintenance of computer, the common sense of network and commonly used software such as Word, Excel, etc.). (2) Computer Basis (2), which is compulsory course for Arts students. This course teaches more advanced computer application technology including seven modules: network, multimedia, database, VB, ASP, web making, the making of dynamic web pages.

In addition, over the years the domestic scholars have carried on the extensive research to teaching models such as "team teaching", "cooperative learning" and so on. And the informatization instructional design is a kind of novel teaching method that has the potential for development. Professor Gaowen and his team from Normal University of East China, Professor Sheng QunLi from Zhejiang University also research and practice informatization instructional design. At present in many universities the bilingual teaching has been effectively carried out. The undergraduate courses of the School of Management and the School of Lingnan at Yatsen University have adopted the original books of Harvard University, Massachusetts institute of technology and 
other famous universities in the United States. In Tsinghua University, 74 out of 1504 courses opened in 2010 were taught in English (including assignments and exams). About 600 core courses adopted foreign famous books as the reference material. More than 80 courses in Beijing University are taught bilingually. The 2010 bilingual class of the Computer Department in South China University of technology made their own class website and opened a BBS.

There are also numerous research on teaching mode abroad such as the accept teaching model represented by Dewey, Bruner and Ausubel in America, program teaching mode by Skinner, non-directive teaching mode by Rogers and so on. They broke the single teaching mode and moved towards diversification. The teaching idea has moved from teachingcentered to learning-centered, from the cognitive target to combining emotion goal, from acquiring knowledge to exploring knowledge, from induction to deduction.

\section{The Exploration of the Teaching Mode Reform of the Basic Comput- er Courses}

Freshmen have different degrees of basic computer knowledge and different majors have different requirements for the content of computer knowledge. In order to learn these differences, I collect the information of different majors through the investigation website, compute and compile the collected information as shown in figure 1.

In the process of the exploration and analysis of the new teaching model, I summed up the following implementation methods for reference.

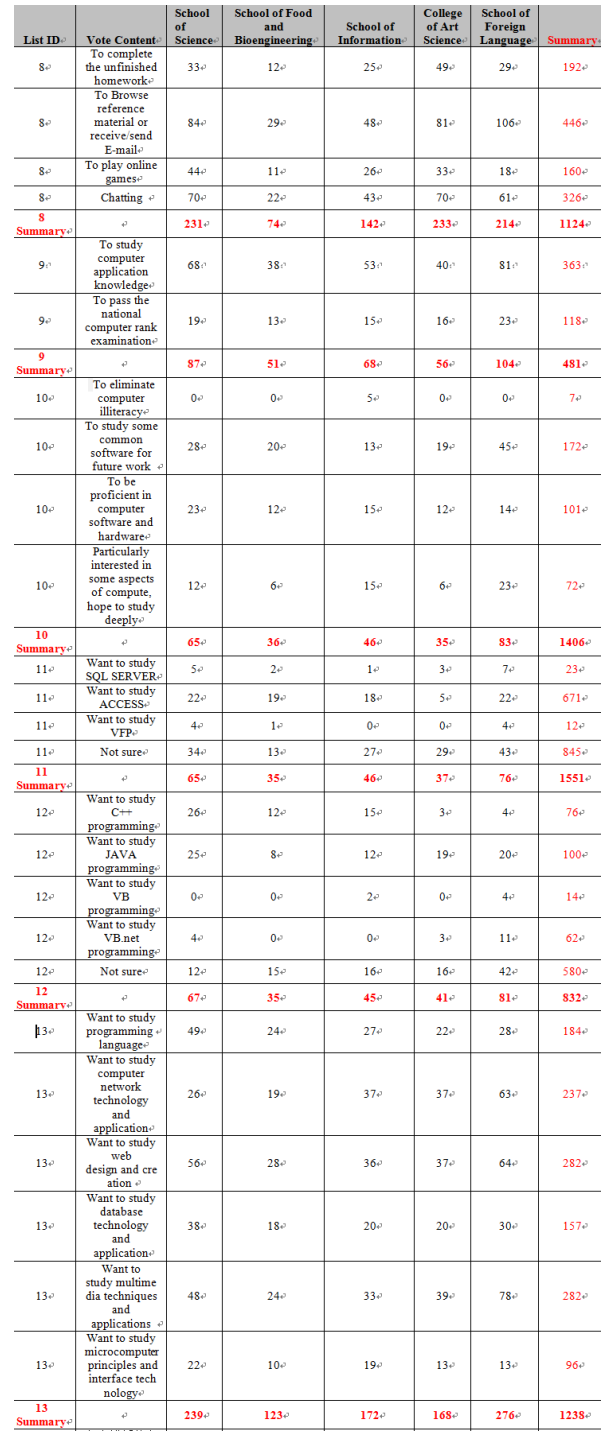

Fig. 1: part of the investigation summary table of different colleges

\subsection{Innovate the teaching ideas, im- prove the teaching content}

First, make students have more access to the computer lab and organize student extracurricular practice on computer. Second, enrich the content of experiment teaching. Add more design, comprehensive and innovative experiments. Third, 
establish the credits of innovative practice, by which, students can complete the corresponding requirements of the course training goal through competition of science and technology and all kinds of innovation plan. Combine the multimedia classroom teaching and the web-assisted instruction, strengthen teacher's leading role, and emphasize the link of practice.

\subsection{To keep pace with the times and update the teaching means}

Because computer public basic course is in fact to cultivate the students' application ability of the computer, the following work can be considered:

First, transfer part of the theoretical courses to practice teaching environment. Use heuristic and interactive method and let the student cooperate with teacher's teaching instance of imitation at the same time learn theory knowledge, which not only improves the students' grasp of theoretical knowledge as well as learning enthusiasm.

Second, organizing the teaching content according to the need of the application (i.e., goal-driven). Guide the students to grasp the method to analyze problems, and the ability to achieve goals with the knowledge instead of focusing on the content itself.

Third, strengthen the case teaching and add the amount of information of theoretical teaching. The information should be the content of the field and the related technical level, so that it can expand students' knowledge, which is very important for the student to obtain the ability to apply the knowledge in real. The link requires teachers to frequently optimize the teaching content and teaching plan and make corresponding changes to teaching files such as Lesson plans and courseware in a timely manner.

Fourth, introduce new interactive methods such as constructing platform for teaching content information website,
BBS etc., in order to increase communication between teachers and students.

Fifth, take the teaching mode based on "original foreign materials + English courseware and blackboard-writing+ Chinese-based English complement teaching + English question answer practice". Select foreign materials with Chinese translation to make bilingual teaching the assistant instead of a barrier for students.

We developed a website suitable for noncomputer majors to learn computer course, which greatly complements the high level of demand in teaching. Website construction contains the handouts, experiment instruction, the network curriculum, as well as material database for self-study, test database, and the exam system and software. All of these have their respective sui generis and are also interconnected so that various teaching forms complement with each other and give full play to their strengths to meet the needs students in different levels and majors.

\subsection{The reform of evaluation method}

We set out to reform the evaluation method and the term score includes computer operation grade, peacetime grade and written test results. The written test results focus on the mastering of the theoretical knowledge, computer operation is a sign of operation skills, and peacetime grade is strict requirement for students. This method can avoid the situation that students blindly pursue high score by rote learning computer, and can thus inspire students to pursue innovative and comprehensive knowledge. In addition, if possible, add the oral examination. For example, bilingual teachers can prepare several topics related to professional computer English in the teaching process for students to give a brief answer, and then give a grade in class. These questions should be simple and close to the 
course as far as possible. Specific assessment measures are as follows:

First, for the assessment of the college computer culture basis, develop stable and perfect online exam system, create a course test question database, automatic marking test, group $1 \sim 2$ times per semester school-wide ability examinations. Second, change the traditional resultdecides-success evaluation practice and emphasize process and the concept of educating people. Strengthen the multiple evaluations of the theoretical teaching process (such as preview, classroom interaction, after class discussion etc.) and experiment teaching process (such as experiment scheme, relevant knowledge preparation, operation situation, work attitude, results, etc.). Third, encourage students to participate in extracurricular activities such as the competitions related to the computer, students' scientific research, teachers' scientific research, the innovation plan such as teachers' scientific research project, the innovation plan activities and formulate the corresponding credit conversion mechanism.

\section{The Notes in the Process of Teach- ing Mode Reform of Basic Comput- er Courses}

- Different majors have different focuses of the basic computer course. For example, some majors with strong engineering are more related to scientific computing and Arts majors may focus on multimedia processing.

- Adjust the proportion of the compulsory courses and elective courses. For example, for some science specialties, basic computer courses should include introduction to computing, data structure and algorithm. For other science specialties rarely involved in programming, compulsory courses can contain only introduction to computing.

- Teaching content should highlight applicability and enjoyment. A variety of methods can be used to stimulate students' learning interest and enthusiasm. For example, when teaching the chapter of "computer network composition and function", I adopted the form of the game to test students' mastering of professional terms. I wrote the important terms on the blackboard in English. Students answered questions in pair, a person explaining to the class and the other one guessing. Within the limited time, the group with the most correct guesses would win. At the beginning some students were timid, but with the encouragement the performance was good.

- Exert the emotional elements of classroom instruction. Teaching practice shows that some students "live in the Cao camp but with their hearts in the han camp". Some students reflect that their study is boring, and couldn't keep up with teaching progress. In fact, the teaching process is not only the information communication between teachers and students, but also emotional communication. Teachers cannot ignore the importance of the emotional influence on the students while focusing on imparting knowledge. Therefore, in the bilingual teaching of the computer, the emotional communication must be noticed and students dare to communicate their mind only in a harmonious relationship between teachers and students.

\section{Conclusion}

Based on the investigation of the basic computer culture study, this paper dis- 
cusses some issues related to the teaching reform, and discusses how to build reasonable and perfect teaching system of basic computer courses. The reform of the teaching pattern of the basic computer courses is still a long-term and difficult education goal, as well as a huge and complicated project. In the process of achieving this goal, there are numerous problems to be solved. Better teaching methods and teaching mode need further exploration and summary in the teaching practice.

\section{References}

[1] Zheng ruiyin, Long quansheng, "The research of Basic Computer Course Teaching Reform Measures," Educational research, vol.22, 2011.

[2] Wang fang, "Network Teaching Mode Research and Status Analysis," Computer CD Software and Applications, vol.20, 2011.

[3] Lerong Jiang, "Research-Oriented Teaching Mode and the Reform in Education of Marxism Principles in Modern Information Environment," Communications in Computer and Information Science, vol. 217, pp.133137, 2011. 